\title{
High-dose-rate Brachytherapy as Adjuvant Local rEirradiation for Salvage Treatment of Recurrent breAst cancer (BALESTRA): a retrospective mono- institutional study
}

\author{
Andrea Vavassori, MD', Giulia Riva, MD ${ }^{*}, 2$, lacopo Cavallo, MD'.3, Ruggero Spoto, MD*, Samantha Dicuonzo, MD', \\ Cristiana Fodor, MScl, Stefania Comi, MSc', Raffaella Cambria, MSc', Federica Cattani, MSc', Anna Morra, MD', \\ Maria Cristina Leonardi, MD!, Roberta Lazzari, MD', Mattia Intra, MD5, Alberto Luini, MD5 , Viviana Enrica Galimberti, MD5, \\ Paolo Veronesi, MD ${ }^{5}$, Roberto Orecchia, MD6, Barbara Alicja Jereczek-Fossa, MD1,3 \\ 'Department of Radiotherapy, IEO European Institute of Oncology IRCCS, Milan, Italy, ${ }^{2}$ Clinical Department, National Center for Oncological \\ Hadrontherapy (CNAO), Pavia, Italy, ${ }^{3}$ University of Milan, Department of Oncology and Hemato-Oncology, Milan, Italy, ${ }^{4}$ Unit of Medical \\ Physics, IEO European Institute of Oncology IRCCS, Milan, Italy, ${ }^{5}$ Department of Breast Surgery, IEO European Institute of Oncology IRCCS, \\ Milan, Italy, 'bsientific Directorate, IEO European Institute of Oncology IRCCS, Milan, Italy \\ *Affiliation at the time of the study
}

\begin{abstract}
Purpose: To evaluate clinical results of catheter-based interstitial high-dose-rate (HDR) brachytherapy (BT) as adjuvant treatment in previously irradiated recurrent breast cancer.

Material and methods: Between January 2011 and September 2015, 31 consecutive patients with histologically confirmed recurrent breast cancer after conservative surgery and conventional whole breast radiotherapy, were retreated with a second conservative surgical resection and reirradiated with adjuvant interstitial HDR-BT. None of the brachytherapy implant was performed during the quadrantectomy procedure. A dose of 34 Gy in 10 fractions, 2 fractions per day, with a minimal interval of 6 hours was delivered.

Results: At the time of the implant, the median age of patients was 59.7 years (range, 39.3-74.9 years). The median time from first treatment until BT for local recurrence was 11.9 years (range, 2.5-27.8 years). The median interval between salvage surgery and BT was 3.6 months (range, 1-8.2 months). No acute epidermitis or soft tissue side effects higher than grade 2 were recorded, with good cosmetic results in all patients. Most of the patients presented grade 1-2 late side effects. Only one patient developed grade 3 liponecrosis. After a median follow-up of 73.7 months (range, 28.8-102.4 months), the overall survival and cancer specific survival were $87.1 \%$ and $90.3 \%$, respectively; 5 -year local control and 5-year progression-free survival rate were $90.3 \%$ and $83.9 \%$, respectively.

Conclusions: Our preliminary analysis showed that HDR-BT is a feasible treatment for partial breast reirradiation offering very low complications rate and fast procedure. Higher patients' cohort is warranted in order to define the role of this treatment modality in the breast conservative management of local recurrence.
\end{abstract}

J Contemp Brachytherapy 2020; 12, 3: 207-215 DOI: https://doi.org/10.5114/jcb.2020.96860

Key words: interstitial HDR brachytherapy, breast cancer recurrence, reirradiation.

\section{Purpose}

Locally recurrent breast cancer after conservative surgery and adjuvant whole-breast external beam radiotherapy (EBRT) is an uncommon event, which historically has been reported in around $6 \%$ in node-negative patients (or less, as in the control arm of ELIOT - intraoperative radiotherapy with electrons trial) and in $10 \%$ in node-posi- tive patients at 5 years, or even lower in more recent trials [1,2]. Studies of the patterns of failure after conservative approach demonstrated that the same quadrant as the primary tumor is most frequently affected by an ipsilateral breast tumor recurrence (IBTR). Whatever it is seen as a true relapse or as a new tumor, the standard of care is mastectomy, with or without post-operative reirradiation, which ensure a local control of $68-98 \%$. Alternative
Address for correspondence: Iacopo Cavallo, MD, Department of Radiotherapy, European Institute of Oncology IRCCS, Via Ripamonti 435, 20141, Milan, Italy, phone: +39 0257483037, e-mail: iacopo.cavallo@ieo.it
Received: 03.03 .2020

Accepted: 13.04 .2020

Published: 30.06 .2020 
approaches are under investigation $[3,4,5,6,7,8,9]$. According to a recent review, after a second breast conserving surgery (SBCS) alone, the weighted rates for 5-year local control, distant metastasis-free survival, and overall survival were $76 \%, 73 \%$, and $77 \%$, respectively [10].

At our institute, after a SBCS approach, recurrent tumor size $\leq 2 \mathrm{~cm}, \mathrm{Ki}-67<20 \%$, and time to relapse $>48$ months were associated with an increased diseasefree survival, whereas absence of estrogen receptors affected overall survival [11,12].

The addition of a further course of adjuvant radiotherapy after SBCS might reduce the risk of local recurrence, and some recent guidelines have strongly suggested to consider the conservative approach including reirradiation along with salvage mastectomy. The possibility of an early diagnosis and the availability of high precision EBRT techniques offered by current technological advances has paved the way for salvage breast conservation based on wide local excision partial breast reirradiation $[13,14,15,16,17,18,19,20,21,22,23,24,25]$.

The conservative approach can be proposed after careful evaluation of surgical feasibility, which must consider the IBTR dimension, size, focality, and the breast size in order to achieve cosmetically acceptable results. Several authors have described the use of adjuvant breast reirradiation with brachytherapy (BT) $[26,27,28,29,30,31,32,33,34,35,36,37,38,39,40]$, intraoperative radiation therapy (IORT) $[41,42,43,44,45,46]$, proton beam radiotherapy $[47,48]$, or EBRT with or without concurrent hyperthermia to increase local control rate $[49,50,51,52,53,54]$.

Brachytherapy can be delivered using low-dose-rate (LDR), pulsed-dose-rate (PDR), or high-dose-rate (HDR) modality. While with LDR technique irradiation is delivered continuously, with HDR and PDR BT the dose is given with a fractionation schedule using afterloading equipment [55].

The purpose of this study, called BALESTRA (Brachytherapy as Adjuvant Local rEirradiation for Salvage Treatment of Recurrent breAst cancer), was to report on acute and late toxicity and preliminary outcome of a single-institution experience of accelerated partial breast reirradiation with adjuvant interstitial HDR-BT.

\section{Material and methods}

\section{Patient, tumor, and treatment characteristics}

The inclusion criteria were as follow: 1 . Patients treated with a SBCS for ipsilateral unicentric in-breast-recurrence after conservative surgery and adjuvant wholebreast EBRT; 2. Multidisciplinary tumor board to confirm the treatment strategy; 3 . Written informed consent. In addition, patients gave consent for the use of their anonymized data for research and educational purposes. Patients' evaluation included complete medical history and physical examination. For each patient, tumor (primary and recurrence) and treatment characteristics, such as histology, recurrence site, TNM classification [56], time interval between primary tumor and relapse, doses of EBRT, and BT implant features were collected.
All the procedures were carried out using afterloading technique under local or general anesthesia. Stainless steel guide needles and/or vascular catheters were implanted through the skin, parallel to the chest wall and to each other, under ultrasound and manual control. Subsequently, polyethylene afterloading catheters were inserted through each needle into the tissue followed by removal of the needles themselves. All the catheters were secured using plastic buttons without skin sutures. Once the implantation was completed, a computed tomography (CT) scan with $2.5 \mathrm{~mm}$ slice thickness and separation was performed and entered into BT treatment planning system (Oncentra Brachy Planning, Nucletron-Elekta) allowing reconstruction of the catheters, definition of the target volumes and of the nearby organs at risk. No patients received intravenous contrast. The clinical target volume (CTV) included nearly $1-2 \mathrm{~cm}$ of healthy breast tissue around the tumor bed in all directions, with a distance between the implant and thoracic wall and/or skin of at least 5-7 mm [57,58,59,60]. Computerized optimization of dwell positions and times of stepping source was performed for fine tuning of isodose distributions. Treatment was delivered using an HDR afterloader (MicroSelectron, Nucletron-Elekta), containing a single Iridum-192 ( ${ }^{192} \mathrm{Ir}$ ) source. Before every BT session, the implant was examined to ensure that there was no critical displacement of the catheters. A total dose of $34 \mathrm{~Gy}$ in 10 fractions, 2 fractions per day, with a minimum interval of 6 hours in-between was administrated. At the end of the last fraction, the implant catheters were removed.

\section{Endpoint analysis}

All patients were followed up every three to six months to analyze acute and late toxicity, according to the Radiation Therapy Oncology Group/European Organization for Research and Treatment of Cancer (RTOG/ EORTC) scoring system [61], local control, and survival. The median follow-up was calculated from the end of BT to the last clinical observation. Local control (LC), which was defined as the absence of disease in the breast after conservative salvage surgery and BT. Progression-free survival (PFS) was calculated from the salvage surgery to the time of local, nodal and/or distant relapse, or death due to breast cancer, whichever occurred first. Cancer specific survival (CSS) and overall survival (OS) were calculated from the salvage surgery to the time of death due to breast cancer and death due to any cause, respectively.

Cosmetic results were reported using the National Surgical Adjuvant Breast and Bowel Project (NSABP)/ RTOG breast cosmesis grading scale: excellent, good, fair, and poor [62].

\section{Results}

Between January 2011 and September 2015, 31 consecutive patients with histologically confirmed IBTR were treated with adjuvant interstitial HDR-BT. Patients, tumor, and treatments characteristics are listed in Table 1. Median age at first diagnosis was 46 years (range, 36.161.4 years). Initial surgical treatment was quadrantectomy and sentinel node biopsy with or without axillary 
Table 1. Patients and tumor characteristics

Characteristics ( $n=31$ patients)

\begin{tabular}{|c|c|c|c|}
\hline & & & \\
\hline \multirow[t]{4}{*}{ Age } & $<50$ years & $20(65)$ & $7(23)$ \\
\hline & $50-60$ years & $9(29)$ & $9(29)$ \\
\hline & $>60$ years & $2(6)$ & $15(48)$ \\
\hline & Median (range) & 46 years (range, 36.1-61.4) & 59.7 years (range, 39.3-74.9) \\
\hline \multirow{4}{*}{$\begin{array}{l}\text { Time to IBTR } \\
\text { (between first and second con- } \\
\text { servative surgery) }\end{array}$} & $<5$ years & - & $4(13)$ \\
\hline & $5-10$ years & - & $9(29)$ \\
\hline & $>10$ years & - & $18(58)$ \\
\hline & Median (range) & - & 11.9 years (range, $2.5-27.8$ ) \\
\hline \multirow[t]{2}{*}{ IBTR site } & True marginal & - & $22(71)$ \\
\hline & Elsewhere & - & $9(29)$ \\
\hline \multirow[t]{4}{*}{ pT stage } & pTis & $4(13)$ & $1(3)$ \\
\hline & pT1 & $16(51)$ & $28(91)$ \\
\hline & pT2 & $7(23)$ & $2(6)$ \\
\hline & Data not available & $4(13)$ & - \\
\hline \multirow[t]{3}{*}{ pN status } & Positive & $11(35)$ & $1(3)$ \\
\hline & Negative & $14(45)$ & $11(36)$ \\
\hline & Data not available & $6(20)$ & $19(61)$ \\
\hline \multirow[t]{4}{*}{ Stage } & 0 & $3(10)$ & $1(3)$ \\
\hline & I & $13(42)$ & $26(84)$ \\
\hline & II & $11(35)$ & $4(13)$ \\
\hline & Data not available & $4(13)$ & - \\
\hline \multirow[t]{6}{*}{ Histological type } & Ductal invasive & $18(58)$ & $21(68)$ \\
\hline & Lobular invasive & $6(20)$ & $6(20)$ \\
\hline & Ductal and lobular & $1(3)$ & - \\
\hline & In situ & $3(10)$ & $1(3)$ \\
\hline & Other & $2(6)$ & $2(6)$ \\
\hline & Data not available & $1(3)$ & $1(3)$ \\
\hline \multirow[t]{4}{*}{ Histological grade } & 1 & $3(10)$ & $2(6)$ \\
\hline & 2 & $10(32)$ & $17(54)$ \\
\hline & 3 & $10(32)$ & $6(20)$ \\
\hline & Data not available & $8(26)$ & $6(20)$ \\
\hline \multirow[t]{3}{*}{ Ki-67 } & $\geq 20 \%$ & $9(29)$ & $20(65)$ \\
\hline & $<20 \%$ & $9(29)$ & $9(29)$ \\
\hline & Data not available & $13(42)$ & $2(6)$ \\
\hline \multirow{4}{*}{$\begin{array}{l}\text { Hormonal receptor status } \\
\text { (estrogen and progesterone) }\end{array}$} & Both positive & $18(58)$ & $21(68)$ \\
\hline & Only one positive & $1(3)$ & $5(16)$ \\
\hline & Both negative & $4(13)$ & $4(13)$ \\
\hline & Data not available & $8(26)$ & $1(3)$ \\
\hline \multirow[t]{3}{*}{ c-erb2 } & Positive & $3(10)$ & $11(35)$ \\
\hline & Negative & $1(3)$ & - \\
\hline & Data not available & $27(87)$ & $20(65)$ \\
\hline \multirow[t]{3}{*}{ Hormonal therapy } & Yes & $18(59)$ & $21(68)$ \\
\hline & No & $11(35)$ & $10(32)$ \\
\hline & Data not available & $2(6)$ & $0(0)$ \\
\hline \multirow[t]{3}{*}{ Chemotherapy } & Yes & $12(39)$ & $5(16)$ \\
\hline & No & $17(55)$ & $24(78)$ \\
\hline & Data not available & $2(6)$ & $2(6)$ \\
\hline
\end{tabular}

Primary, $n(\%)$

BTR, $n$ (\%)

$7(23)$

IBTR - ipsilateral breast tumor recurrence 
dissection, and the median time to SBCS was 11.9 years (range, 2.5-27.8 years). The median dose of previous radiation therapy was $60 \mathrm{~Gy}$ (range, 50-66 Gy).

Ipsilateral breast tumor recurrence occurred at or near the same quadrant in $22(71 \%)$ patients, while in $9(29 \%)$ patients was detected in a different quadrant of the breast. Primary tumor and locally IBTR showed the same histological type in 18 (58\%) patients, while this information remained unknown for 2 patients $(6.4 \%)$.

Histological grade 3 was found in $10(32 \%)$ and $6(20 \%)$ patients with primary tumor and IBTR, respectively. A second surgical axillary staging was performed in only 12 patients (39\%).

None of the BT implant was performed during a surgical procedure; the median interval between salvage surgery and BT was 3.6 months (range, 1-8.2 months).

The median number of catheters and planes was 9 (range, 6-25 catheters) and 2 (range, 1-4 planes), respectively. Dosimetric records were accessible for all, except for one patient. No technical problems, such as collapses or kinking of flexible catheters allowing temporary or definitive breakdowns of treatment were recorded. Radioprotection of staff was completed for each application. No complications involving the implant, such as bleeding or infection were noted. The procedure was well tolerated in all patients. None of the patients experienced severe pain or discomfort during treatment, and no BT-related infection was observed.
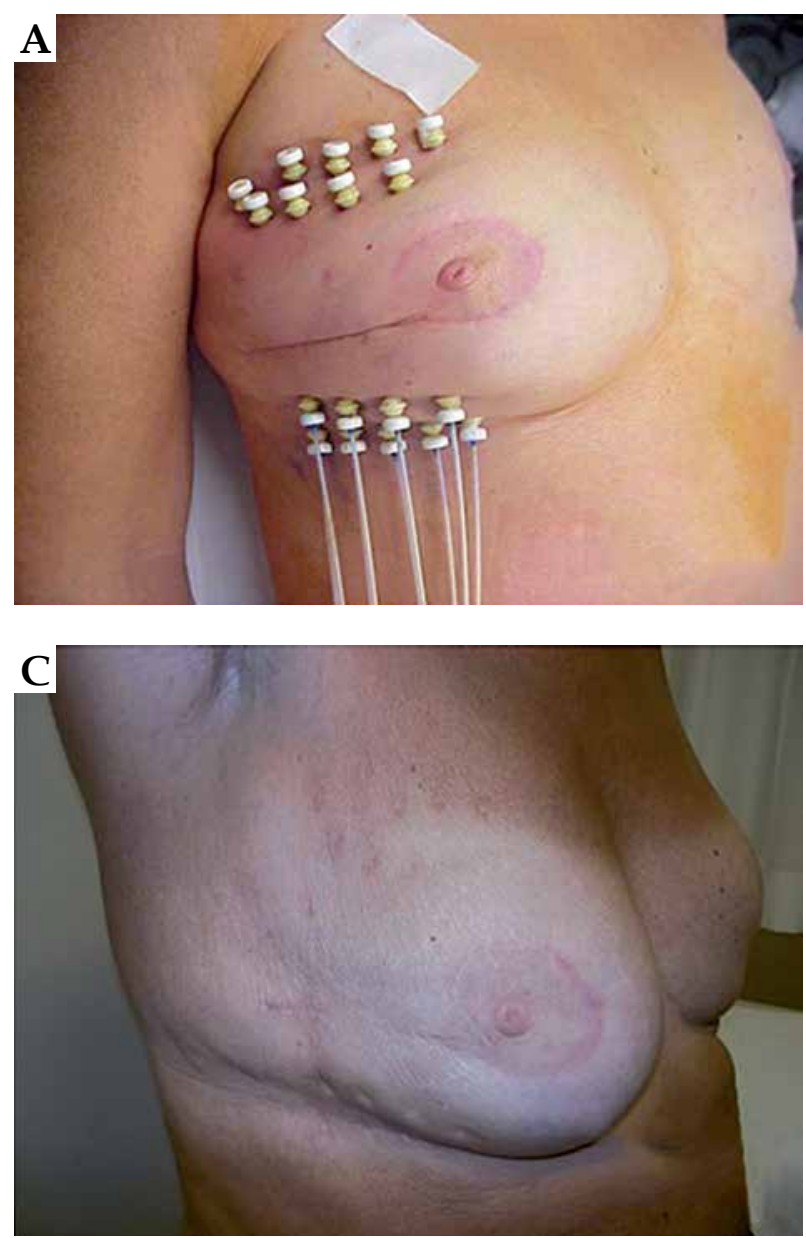

\section{Local control and survival rates}

No patients were lost to follow-up. After a median follow-up of 73.7 months (range, 28.8-102.4 months), OS and CSS were $87.1 \%$ and $90.3 \%$, respectively; 5-year LC and 5-year PFS were $90.3 \%$ and $83.9 \%$, respectively.

Further IBTR with or without concomitant regional and/or distant metastases occurred in 3 patients (9.7\%) after 32, 39, and 44 months from SBCS: two of them were successfully salvaged with mastectomy, while a patient with concomitant distant metastasis received chemotherapy only. Two patients developed distant metastases.

All but one of patients with a second relapse and/or metastasis had a Ki- $67 \geq 20 \%$ at first IBTR ( 4 out of 20 patients, $20 \%)$. Three of them had a histological G3 primary tumor ( 3 out of 10 patients, 30\%) and developed the IBTR in a quadrant other than the initial primary cancer ( 3 out of 9 patients, $33 \%$ ).

Due to small number of patients, we did not find any other association between second relapse and tumor stage, histologic type, hormonal receptor status, or dosimetric parameters.

\section{Morbidity and cosmetic results}

No acute skin or soft tissue side effects higher than grade 2 were recorded, all were treated topically. All patients presented good cosmetic results (Figure 1).

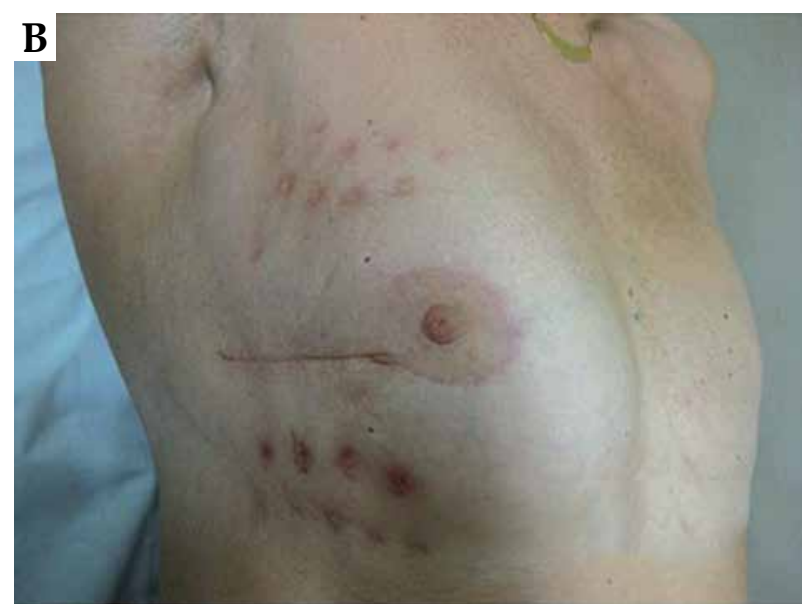

Fig. 1. A) Multicatheter interstitial implants; B) Follow-up at 1 month; C) Follow-up at 1 year 
Table 2. Late toxicities ( $\geq 6$ months after BT) observed during follow-up ( $n=31$ patients)

\begin{tabular}{lcccc} 
& Grade 0 & Grade 1 & Grade 2 & Grade 3 \\
\hline Edema & $27(87.1 \%)$ & $3(9.7 \%)$ & 0 & $1(3.2 \%)$ \\
\hline Fibrosis & $7(22.5 \%)$ & $16(51.6 \%)$ & $8(25.8 \%)$ & 0 \\
\hline Telangiectasia & $26(83.9 \%)$ & $4(12.9 \%)$ & $1(3.2 \%)$ & 0 \\
\hline Retraction & $24(77.4 \%)$ & $5(16.1 \%)$ & $2(6.4 \%)$ & 0 \\
\hline Skin atrophy & $27(87.1 \%)$ & $4(12.9 \%)$ & 0 & 0
\end{tabular}

Probably, their unexpectedly positive judgment was intrinsically and psychologically influenced by the conservative result (even with a second surgery and a reirradiation) compared to the one they would have had if they had had to undergo a mastectomy.

Most patients showed mild late side effects (grade $\leq 2$ ), cutaneous and sub-cutaneous fibrosis $(77.4 \%)$, retraction $(24 \%)$, and telangiectasia $(13.7 \%)$; only one patient developed grade 3 breast edema (Table 2). Asymptomatic fat necrosis was detected in one patient and required no surgical intervention. As stated by Wazer and colleagues, skin and subcutaneous toxicities (including fibrosis) are usually associated with the $\mathrm{V}_{150}$ and $\mathrm{V}_{200}$, and inversely associated with the dose homogeneity index (DHI): DHI $=\left(\mathrm{V}_{100}-\mathrm{V}_{150}\right) / \mathrm{V}_{100}$, where $\mathrm{V}_{100}, \mathrm{~V}_{150}$, and $\mathrm{V}_{200}$ are CTV volumes receiving $100 \%, 150 \%$, and $200 \%$ of the prescribed dose, respectively [63].

In the group of patients with grade 2 fibrosis and in the group with G0-G1 fibrosis, the median $\mathrm{V}_{150}, \mathrm{~V}_{200}$, and DHI were $17.1 \mathrm{~cm}^{3}$ and $16.5 \mathrm{~cm}^{3}, 7.5 \mathrm{~cm}^{3}$ and $7.6 \mathrm{~cm}^{3}$, and 0.27 and 0.4 , respectively. The patient with fat necrosis received a large BT implant with 18 catheters in 3 planes; her $\mathrm{V}_{150}$ and $\mathrm{V}_{200}$ were $59.9 \mathrm{~cm}^{3}$ and $30.2 \mathrm{~cm}^{3}$, respectively (Table 3). Late breast or chest wall pain of grade 2-3 were reported in 4 patients. No pleuritis, pneumonitis, pericarditis, or rib fracture were observed.

\section{Discussion}

Local failure after breast conserving surgery and radiotherapy represents a challenge for surgeons and radiation oncologists to minimize morbidity while maintaining optimal treatment outcomes. The importance of quality of life and body image require a mandatory attention given to conservative surgical treatment of local recurrence.

Compared to EBRT, the main advantages of BT, with the radiation sources directed on the tumor bed, include a higher localized dose around the target volume and a shorter overall treatment time. The rapid fall-off of doses around sources allows relative sparing of critical normal tissues. The main disadvantage of the partial breast reirradiation is the potential not-treatment of cancer occult foci in areas of the breast outside the implanted volume. Our analysis showed that adjuvant HDR-BT is a feasible treatment for recurrent breast cancer, offering low complications rate and good cosmesis. At last follow-up, the OS and PFS were $87.1 \%$ and $83.9 \%$, respectively, with LC of $90.3 \%$.
We have observed an increased risk of second relapse or metastasis in patients with a histological G3 primary tumor and/or an aggressive IBTR (Ki-67 $\geq 20 \%$ ) developed in a quadrant other than the initial primary cancer. We were aware of the several limitations of a single center retrospective analysis. Nevertheless, the data reported in this cohort showed excellent local control and survival rates, comparing very favorably with other published reports on HDR interstitial BT for treatment of IBTR with heterogeneous fractionation schemes and doses (Table 4).

Niehoff et al. reported on 32 consecutive patients, who were affected by local recurrence after mastectomy (13 patients) or breast-conserving surgery (19 patients) and fulldose adjuvant EBRT. Reirradiation was performed with HDR (15 patients; mean dose, $28 \mathrm{~Gy} ; 2 \times 2.5 \mathrm{~Gy} /$ day, with 6 hours interfractional interval daily) or PDR-BT (17 patients; mean dose, $30 \mathrm{~Gy} ; 5 \times 1$ Gy/day, with 2 hours of pulse intervals). After a mean follow-up of 19 months, local control was achieved in 20 patients, but 20 of the 32 patients experienced an additional systemic progression [27].

Guix et al. reported on 36 patients with local recurrence after conservative treatment for breast cancer, treated by a second lumpectomy, and followed by adjuvant HDR-BT (30 Gy in 12 fractions in 5 days). Actuarial LC, DFS, and OS at 10 years were $89.4 \%, 64.4 \%$, and $96.7 \%$, respectively [32]. In 2011, the same group published an update on 85 patients with breast-only recurrence: 48 pa-

Table 3. Implant parameters ( $n=30$ patients)

Median (range)

\begin{tabular}{lc}
\hline Number of catheters & $9(6-25)$ \\
\hline Number of planes & $2(1-4)$ \\
\hline Volume of CTV & $32.9 \mathrm{~cm}^{3}\left(9.1-143 \mathrm{~cm}^{3}\right)$ \\
\hline $\mathrm{V}_{100}$ & $30.6 \mathrm{~cm}^{3}\left(9.1-137 \mathrm{~cm}^{3}\right)$ \\
\hline $\mathrm{V}_{150}$ & $16.5 \mathrm{~cm}^{3}\left(7.8-101 \mathrm{~cm}^{3}\right)$ \\
\hline $\mathrm{V}_{200}$ & $7.6 \mathrm{~cm}^{3}\left(2.8-30.2 \mathrm{~cm}^{3}\right)$ \\
\hline$D_{90}$ & $41.4 \mathrm{~Gy}(27.5-53.4 \mathrm{~Gy})$ \\
\hline DHI & $0.4(0.1-0.7)$ \\
\hline Treatment duration & 6 days $(5-8)$
\end{tabular}

$C T V$ - clinical target volume, $D H I$ - dose homogeneity index, $D_{90}$-dose to $90 \%$ of CTV, $V_{100}$ - volume of CTV encompassed by $100 \%$ isodose, $V_{150}$-volume of CTV encompassed by $150 \%$ isodose, $V_{200}$-volume of CTV encompassed by $200 \%$ isodose 
Table 4. Overview of relevant publications on salvage BT

\begin{tabular}{|c|c|c|c|c|}
\hline Reference & $\begin{array}{l}\text { Number } \\
\text { of patients }\end{array}$ & Treatment modality & Follow-up & Clinical results \\
\hline Resch et al. [26] & 17 & $\begin{array}{l}8 \text { pts, EBRT } 12-30 \text { Gy + } \\
\text { PDR boost } 12.5-28 \text { Gy } \\
9 \text { pts, PDR } 40.2-50 \text { Gy }\end{array}$ & $\begin{array}{l}59 \text { months } \\
\text { (range, 20-84 months) }\end{array}$ & LC, $70.5 \%$ \\
\hline Niehoff et al. [27] & $\begin{array}{c}32 \\
\text { (13 patients post-mas- } \\
\text { tectomy) }\end{array}$ & $\begin{array}{c}15 \text { HDR, } \\
\text { mean dose, } 28 \text { Gy } \\
17 \text { PDR, } \\
\text { mean dose, } 30 \text { Gy }\end{array}$ & 19 months & $\begin{array}{l}\mathrm{LC}, 20 \mathrm{pts} \\
\mathrm{M}+, 32 \mathrm{pts}\end{array}$ \\
\hline Chadha et al. [28] & 15 & $\begin{array}{c}\text { LDR, } \\
\text { total dose, } 30-45 \text { Gy }\end{array}$ & 36 months & $\begin{array}{c}\text { 3-year OS, } 100 \% \\
\text { MFS, } 89 \%\end{array}$ \\
\hline Trombetta et al. [29] & 21 & $\begin{array}{c}\text { LDR, } \\
\text { total dose, } 45-55.3 \text { Gy }\end{array}$ & $\begin{array}{l}40 \text { months } \\
\text { (range, 3-69) }\end{array}$ & $\begin{array}{l}\text { LC, } 95.2 \% \\
\text { OS, } 90.4 \%\end{array}$ \\
\hline Polgar et al. [30] & 12 & $\begin{array}{c}\text { HDR, } \\
22 \text { Gy; } 5 \text { fractions b.i.d. }\end{array}$ & $\begin{array}{c}56 \text { months } \\
\text { (range, 8-112) }\end{array}$ & MFS, $100 \%$ \\
\hline Adkinson et al. [31] & $\begin{array}{c}11 \\
\text { (4 BCa; } 6 \text { HD; } 1 \text { STS) }\end{array}$ & $\begin{array}{c}\text { HDR, } \\
34 \text { Gy; } 10 \text { fractions b.i.d. }\end{array}$ & 53.7 months & $\begin{array}{l}\text { LC, } 100 \% \\
\text { OS, } 100 \% \\
\end{array}$ \\
\hline Hannoun-Levi et al. [33] & 42 & $\begin{array}{c}\text { HDR } \\
34 \text { Gy; } 10 \text { fractions b.i.d. }\end{array}$ & 21 months & LC, $97 \%$ \\
\hline Trombetta et al. [34] & $\begin{array}{c}18 \\
(16 \mathrm{BCa} ; 2 \mathrm{HD})\end{array}$ & $\begin{array}{c}\text { HDR (balloon) } \\
34 \text { Gy; } 10 \text { fractions b.i.d. }\end{array}$ & $\begin{array}{l}39.6 \text { months } \\
\text { (range, 15-74) }\end{array}$ & LC, $89 \%$ \\
\hline Kauer-Dorner et al. [35] & 39 & $\begin{array}{c}\text { PDR, } \\
\text { mean total dose, } 50.1 \text { Gy }\end{array}$ & 57 months & $\begin{array}{l}5 \text {-year LC, 93\% } \\
5 \text {-year OS, 87\% } \\
5 \text {-year DFS, 77\% } \\
\end{array}$ \\
\hline Guix et al. [36] & 48 & $\begin{array}{c}\text { HDR } \\
30 \text { Gy; } 12 \text { fractions b.i.d. }\end{array}$ & - & $\begin{array}{c}\text { LC at } 17 \text { year, } 84.2 \% \\
\text { DFS, } 65.4 \% \\
\text { OS, } 90.7 \%\end{array}$ \\
\hline $\begin{array}{l}\text { Hannoun-Levi et al. } \\
\text { GEC-ESTRO Breast Can- } \\
\text { cer working group [37] }\end{array}$ & 217 & $\begin{array}{l}\operatorname{HDR}(47 \%) \\
\operatorname{PDR}(40.6 \%) \\
\operatorname{LDR}(12.4 \%)\end{array}$ & $\begin{array}{c}46.8 \text { months } \\
\text { (range 13.2-123.6) }\end{array}$ & $\begin{array}{c}\text { 5-year LC, } 94.4 \% \\
10 \text {-year LC, 92.8\% } \\
5 \text {-year OS, 88.7\% } \\
10 \text {-year OS, 76.4\% } \\
5 \text {-year M+, 9.6\% } \\
10 \text {-year M+, 19.1\% }\end{array}$ \\
\hline Cozzi et al. [38] & 40 & $\begin{array}{c}\text { HDR, } \\
32 \text { Gy; } 8 \text { fractions b.i.d. } \\
34 \text { Gy;10 fractions b.i.d. } \\
16 \text { Gy; single fraction }\end{array}$ & $\begin{array}{l}61.5 \text { months } \\
\text { (range, } 6-153)\end{array}$ & $\begin{array}{c}\text { 5-year OS, 85.3\% } \\
\text { 5-year LC, 96.6\% } \\
\text { 5-year M+, 6\% }\end{array}$ \\
\hline Smanyko et al. [39] & 39 & $\begin{array}{c}\text { HDR, } \\
22 \text { Gy; } 5 \text { fractions b.i.d. }\end{array}$ & $\begin{array}{l}59 \text { months } \\
\text { (range, 1-189) }\end{array}$ & $\begin{array}{c}5 \text {-year LC, 94\% } \\
5 \text {-year DFS, 69\% } \\
5 \text {-year OS, 81\% }\end{array}$ \\
\hline Forster et al. [40] & 19 & $\begin{array}{c}\text { HDR (58\%) } \\
\text { 34.2 Gy; } 9 \text { fractions b.i.d. } \\
32 \text { Gy; } 8 \text { fractions b.i.d. } \\
\text { PDR (42\%) } \\
\text { total dose, } 49.8-50.4 \text { Gy }\end{array}$ & $\begin{array}{c}66 \text { months } \\
\text { (range, 18-120) }\end{array}$ & $\begin{array}{c}5 \text {-year LC, } 100 \% \\
5 \text {-year DFS, 100\% } \\
5 \text {-year OS, } 100 \%\end{array}$ \\
\hline Our study & 31 & $\begin{array}{c}\text { HDR, } \\
34 \text { Gy; } 10 \text { fractions b.i.d. }\end{array}$ & $\begin{array}{c}73.7 \text { months } \\
\text { (range, 28.8-102.4) }\end{array}$ & $\begin{array}{c}\text { 5-year LC, } 90.3 \% \\
\text { 5-year DFS, 83.9\% } \\
\text { 5-year OS, 87.1\% }\end{array}$ \\
\hline
\end{tabular}

BCa - breast cancer, b.i.d. - bis in die, DFS - disease-free survival, GEC-ESTRO - Groupe Européen de Curiethérapie and European SocieTy for Radiotherapy and Oncology, HD - Hodgkin disease, HDR - high-dose-rate, LC - local control, LDR - low-dose-rate, MFS - mastectomy-free survival, M+ - systemic progression, OS - overall survival, PDR - pulsed-dose-rate, STS - soft tissue sarcoma

tients were treated by a second lumpectomy followed by adjuvant HDR-BT, whereas 37 patients treated by mastectomy had no further radiotherapy. Actuarial LC, DFS, and OS at 17 -year were $84.2 \%, 71.7 \%$, and $65.4 \%$ for SBCS, and $63.8 \%, 90.7 \%$, and $88.2 \%$ for mastectomy, respectively. Authors concluded that salvage lumpectomy and BT could be considered the treatment of choice in patients with recurrent breast tumors [36]. 
Hannoun-Levi et al. presented clinical results of second conservative treatment of combining surgery and HDR-BT (dose per fraction, 3.4 Gy; total dose, 34 Gy) in 42 patients affected by ipsilateral breast cancer recurrence. After a median follow-up of 21 months, second local control rate was $97 \%$ with acceptable toxicity and high patient satisfaction regarding cosmetic results [33].

The Groupe Européen de Curiethérapie (GEC) and the European Society for Radiotherapy and Oncology (ESTRO) working group published a retrospective study on 217 patients treated with lumpectomy and multi-catheter HDR (47\%), PDR (40.6\%), and LDR (12.4\%) BT in 8 institutions. After a median follow-up of 3.9 years (range, 1.1-10.3 years), 5- and 10-year actuarial LC, OS, and distant metastasis rates were $94.4 \%(90.5-98.5 \%)$ and $92.8 \%$ (87.9$87.9 \%), 88.7 \%$ and $76.4 \%, 9.6 \%$ and $19.1 \%$, respectively, with excellent/good cosmetic result in $85 \%$ of cases [37].

Cozzi et al. evaluated a dataset of 40 patients treated with tumorectomy and interstitial intra- or post-operative HDR-BT with different schemes ( 32 Gy in 8 fractions; $34 \mathrm{~Gy}$ in 10 fractions; $16 \mathrm{~Gy}$ in single fraction). Late fibrosis $>$ grade 3 was observed in 14 patients (35\%). The 3- and 5-year OS was 97 and $85.3 \%$, respectively. Local relapse and metastasis-free survival at 5 years were $96.6 \%$ and $94 \%$, respectively [38]

More recently, Smanyko et al. reported clinical outcomes of 195 patients with ipsilateral breast tumor recurrences treated with SBCS with interstitial BT (39 patients; dose per fraction, $4.4 \mathrm{~Gy}$; total fractions, 5; total dose, $22 \mathrm{~Gy}$ ) or salvage mastectomy (156 patients). After a median follow-up of 6 years, a new local recurrence occurred in $10.2 \%$ and $17.9 \%$, and the 5-year disease-free survival was $69 \%$ and $65 \%$ in the conservative surgery + BT group and in the mastectomy group, respectively. The 5-year probability of overall survival was $81 \%$ vs $66 \%$, respectively [39].

Forster et al. analyzed results of 19 consecutive patients with small, low-risk breast recurrence (rpT1 cN0 cM0, Her2 negative, preferably positive hormone receptor status), treated with SBCS and interstitial multicatheter BT (8 PDR, 11 HDR). After a median follow-up of 65 months, 5-year DFS and OS rates were both 100\%; only one patient had a second in-breast recurrence at 77 months after salvage treatment [40]

Comparable results were showed in smaller BT patient cohorts $[26,30,31,34]$ and in patients treated with other types of adjuvant irradiation. SBCS and IORT presented LC and OS of $91-100 \%$ and $82-94 \%$, respectively $[41,42,43,44,45,46]$, whereas a second EBRT after SBCS provided LC of $76.9-100 \%$ and OS of $62.5-100 \%$ $[49,50,51,52,53]$.

\section{Conclusions}

Despite small sample size, our preliminary results are comparable with literature data related to good feasibility of the technique, low toxicity profile, good tumor control, and encouraging cosmetic results. A close interdisciplinary collaboration between the surgical and radiation oncology communities is required to individualize each treatment and to maximize patient care.
Accelerated partial breast reirradiation using HDRBT offers an alternative to mastectomy in carefully selected patients with a favorable breast recurrence. Further clinical trials are needed to identify possible subgroups of patients that might be suitable for this type of approach.

\section{Acknowledgments}

The authors would like to thank William Russel Edu for his help in literature research.

This work was partially supported by the Italian Ministry of Health with Ricerca Corrente and 5x1000 funds and by a research grant from Accuray Inc. The sponsor did not play any role in the study design, collection, analysis, and interpretation of data, nor in writing of the manuscript or the decision to submit the manuscript for publication.

\section{Disclosure}

The authors report no conflict of interest.

\section{References}

1. Early Breast Cancer Trialists' Collaborative Group (EBCTCG). Effect of radiotherapy after breast-conserving surgery on 10-year recurrence and 15-year breast cancer death: meta-analysis of individual patient data for 10,801 women in 17 randomised trials. Lancet 2011; 378: 1707-1716.

2. Veronesi U, Orecchia R, Maisonneuve P et al. Intraoperative radiotherapy versus external radiotherapy for early breast cancer (ELIOT): a randomised controlled equivalence trial. Lancet Oncol 2013; 14: 1269-1277.

3. Hannoun-Levi JM, Ihrai T, Courdi A. Local treatment options for ipsilateral breast tumor recurrence. Cancer Treat Rev 2013; 39: 737-741.

4. Burger AEE, Pain SJ, Peley G. Treatment of recurrent breast cancer following breast conserving surgery. Breast J 2013; 19: 310-318.

5. Salvadori B, Marubini E, Miceli R et al. Reoperation for locally recurrent breast cancer in patients previously treated with conservative surgery. Br J Surg 1999; 86: 84-87.

6. Komoike $\mathrm{Y}$, Motomura K, Inaji H et al. Repeat lumpectomy for patients with ipsilateral breast tumor recurrence after breast-conserving surgery. Oncology 2003; 64: 1-6.

7. Alpert TE, Kuerer HM, Arthur DW et al. Ipsilateral breast tumor recurrence after breast conservation therapy: outcomes of salvage mastectomy vs. salvage breast-conserving surgery and prognostic factors for salvage breast preservation. Int J Radiat Oncol Biol Phys 2005; 63: 845-851.

8. Ishitobi M, Okumura $Y$, Nishimura R et al. Repeat lumpectomy for ipsilateral breast tumor recurrence (IBTR) after breast-conserving surgery: the impact of radiotherapy on second IBTR. Breast Cancer 2014; 21: 754-760.

9. Houvenaeghel G, Boher JM, Michel V. Survival after breast cancer local recurrence according to therapeutic strategies. Eur J Surg Oncol 2017; 43: 1409-1414.

10. Walstra CJEF, Schipper RJ, Poodt IGM et al. Repeat breast-conserving therapy for ipsilateral breast cancer recurrence: A systematic review. Eur J Surg Oncol 2019; 45: 1317-1327.

11. Gentilini O, Botteri E, Rotmensz N et al. When can a second conservative approach be considered for ipsilateral breast tumour recurrence? Ann Oncol 2007; 18: 468-472.

12. Gentilini O, Botteri E, Veronesi P et al. Repeating conservative surgery after ipsilateral breast tumor reappearance: criteria for selecting the best candidates. Ann Surg Oncol 2012; 19: 3771-3776. 
13. Kuerer HM, Arthur DW, Haffty BG. Repeat breast-conserving surgery for in-breast local breast carcinoma recurrence: the potential role of partial breast irradiation. Cancer 2004; 100: 2269-2280.

14. Trombetta M, Julian TB, Werts ED et al. Comparison of conservative management techniques in the re-treatment of ipsilateral breast tumor recurrence. Brachytherapy 2011; 10: 74-80.

15. Suarez J, Arthur D, Woodward W, Kuerer HM. Breast preservation in patients with local recurrence after breast-conserving therapy. Curr Breast Cancer Rep 2011; 3: 88-96.

16. Siglin J, Champ CE, Vakhnenko Y et al. Radiation therapy for locally recurrent breast cancer. Int J Breast Cancer 2012; 2012: 571946.

17. Sedlmayer F, Zehentmayr F, Fastner G. Partial breast re-irradiation for local recurrence of breast carcinoma: benefit and long term side effects. Breast 2013; 22: S141-146.

18. Vila J, Garcia-Etienne CA, Vavassori A, Gentilini O. Conservative surgery for ipsilateral breast tumor recurrence. J Surg Oncol 2014; 110: 62-67.

19. Harms W, Geretschläger A, Cescato $C$ et al. Current treatment of isolated locoregional breast cancer recurrences. Breast Care 2015; 10: 265-271.

20. Harms W, Budach W, Dunst J et al. Breast Cancer Expert Panel of the German Society of Radiation Oncology (DEGRO). Practical guideline for radiotherapy of breast cancer VI: therapy of locoregional breast cancer recurrences. Strahlenther Onkol 2016; 192: 199-208.

21. Marta GN, Hijial T, de Andrade Carvalho H. Reirradiation for locally recurrent breast cancer. Breast 2017; 33: 159-165.

22. Wadasadawala T, Vadgaonkar R, Bajpai J. Management of isolated locoregional recurrences in breast cancer: a review of local and systemic modalities. Clin Breast Cancer 2017; 17: 493-502.

23. Nieder C, Langendijk JA, Guckenberger M, Grosu AL. Preserving the legacy of reirradiation: a narrative review of historical publications. Adv Radiat Oncol 2017; 2: 176-182.

24. Quivrin M, Peignaux-Casasnovas K, Martin É et al. Salvage brachytherapy as a modern reirradiation technique for local cancer failure: The Phoenix is reborn from its ashes. Cancer Radiother 2018; 22: 372-381.

25. Al-Hilli Z, Grobmyer SR. Management strategies for locally recurrent breast cancer: redo-lumpectomy, redo-sentinel node biopsy, redo-radiation. Ann Surg Oncol 2019; 26: 3018-3024.

26. Resch A, Fellner C, Mock U et al. Locally recurrent breast cancer: pulse dose rate brachytherapy for repeat irradiation following lumpectomy - a second chance to preserve the breast. Radiology 2002; 225: 713-718.

27. Niehoff P, Dietrich J, Ostertag $\mathrm{H}$ et al. High-dose-rate or pulsed-dose-rate perioperative interstitial intensity-modulated brachytherapy for local recurrences of previously irradiated breast or thoracic wall following breast cancer. Strahlenther Onkol 2006; 182: 102-107.

28. Chadha M, Feldman S, Boolbol S et al. The feasibility of a second lumpectomy and breast brachytherapy for localized cancer in a breast previously treated with lumpectomy and radiation therapy for breast cancer. Brachytherapy 2008; 7: 22-28.

29. Trombetta M, Julian TB, Bhandari T et al. Breast conservation surgery and interstitial brachytherapy in the management of locally recurrent carcinoma of the breast: The Allegheny General Hospital experience. Brachytherapy 2008; 7: 29-36.

30. Polgar C, Sulyok Z, Major T et al. Reexcision and perioperative high-dose-rate brachytherapy in the reatment of local relapse after breast conservation: an alternative to salvage mastectomy. J Contemp Brachytherapy 2009; 1: 131-136.

31. Adkison JB, Kuske RR, Patel RR. Breast conserving surgery and accelerated partial breast irradiation after prior breast radiation therapy. Am J Clin Oncol 2010; 33: 427-431.
32. Guix B, Lejarcegui JA, Tello JI et al. Exeresis and brachytherapy as salvage treatment for local recurrence after conservative treatment for breast cancer: results of a ten-year pilot study. Int J Radiat Oncol Biol Phys 2010; 78: 804-810.

33. Hannoun-Levi JM, Castelli J, Plesu A et al. Second conservative treatment for ipsilateral breast cancer recurrence using high-dose rate interstitial brachytherapy: preliminary clinical results and evaluation of patient satisfaction. Brachytherapy 2011; 10: 171-177.

34. Trombetta M, Hall M, Julian TB. Long term follow up of breast preservation by re-excision and balloon brachytherapy after ipsilateral breast tumor recurrence. Brachytherapy 2014; 13: 488-492

35. Kauer-Dorner D, Potter R, Resch A et al. Partial breast irradiation for locally recurrent breast cancer within a second breast conserving treatment: alternative to mastectomy? Results from a prospective trial. Radiother Oncol 2012; 102: 96-101.

36. Guix B, Lejarcegui JA, Tello JI et al. Accelerated partial breast brachytherapy after lumpectomy as salvage treatment for local recurrences after conservative treatment of breast cancer: Eighteen-year results of a nonrandomized comparison with mastectomy. J Clin Oncol 2011; 27 Suppl: 109-109.

37. Hannoun-Levi JM, Resch A, Gal J et al. Accelerated partial breast irradiation with interstitial brachytherapy as second conservative treatment for ipsilateral breast tumor recurrence: Multicentric study of GEC-ESTRO Breast Cancer Working Group. Radiother Oncol 2013; 108: 226-231.

38. Cozzi S, Jamal DN, Slocker A et al. Second breast-conserving therapy with interstitial brachytherapy (APBI) as a salvage treatment in ipsilateral breast tumor recurrence: a retrospective study of 40 patients. J Contemp Brachytherapy 2019; 2: 101-107.

39. Smanyko V, Meszaros N, Ujhelyi M et al. Second breast-conserving surgery and interstitial brachytherapy vs. salvage mastectomy for the treatment of local recurrences: 5-year results. Brachytherapy 2019; 18: 411-419.

40. Forster T, Akbaba S, Schmitt D et al. Second breast conserving therapy after ipsilateral breast tumor recurrence a 10-year experience of re-irradiation. J Contemp Brachytherapy 2019; 11: 312-319.

41. Intra M, Gentilini O, Veronesi P et al. A new option for early breast cancer patients previously irradiated for Hodgkin's disease: intraoperative radiotherapy with electrons (ELIOT). Breast Cancer Res 2005; 7: 828-832.

42. Kraus-Tiefenbacher U, Bauer L, Scheda A et al. Intraoperative radiotherapy (IORT) is an option for patients with localized breast recurrences after previous external-beam radiotherapy. BMC Cancer 2007; 7: 178-184.

43. Blandino G, Guenzi M, Belgioia L et al. Adjuvant intraoperative radiotherapy for selected breast cancers in previously irradiated women: evidence for excellent feasibility and favorable outcomes. Rep Pract Oncol Radiother 2017; 22: 277-283.

44. Thangarajah F, Heilmann J, Malter W et al. Breast conserving surgery in combination with intraoperative radiotherapy after previous external beam therapy: an option to avoid mastectomy. Breast Cancer Res Treat 2018; 168: 739-744.

45. Boehm KM, Chen J, Trichter S et al. Characterization of recurrences following second breast-conserving surgery with intraoperative radiotherapy. Ann Surg Oncol 2020; 27: 1638-1644.

46. Leonardi MC, Tomio L, Radice D et al. Local failure after accelerated partial breast irradiation with intraoperative radiotherapy with electrons: an insight into management and outcome from an italian multicentric study. Ann Surg Oncol 2020; $27: 752-762$.

47. Thorpe CS, Niska JR, Girardo ME et al. Proton beam therapy reirradiation for breast cancer: Multi-institutional prospective PCG registry analysis. Breast J 2019; 6: 1160-1170. 
48. Gabani P, Patel H, Thomas MA et al. Clinical outcomes and toxicity of proton beam radiation therapy for re-irradiation of locally recurrent breast cancer. Clin Transl Radiat Oncol 2019; 19: 116-122.

49. Wahl AO, Rademaker A, Kiel KD et al. Multi-institutional review of repeat irradiation of chest wall and breast for recurrent breast cancer. Int J Radiat Oncol Biol Phys 2008; 70: 477-484.

50. Würschmidt F, Dahle J, Petersen C et al. Reirradiation of recurrent breast cancer with and without concurrent chemotherapy. Radiat Oncol 2008; 3: 28.

51. Deutsch M. Repeat high-dose external beam irradiation for in-breast tumor recurrence after previous lumpectomy and whole breast irradiation. Int J Radiat Oncol Biol Phys 2002; 53: 687-691.

52. Arthur DW, Winter KA, Kuerer HM et al. NRG OncologyRadiation Therapy Oncology Group Study 1014: 1-year toxicity report from a phase 2 study of repeat breast-preserving surgery and 3-dimensional conformal partial-breast reirradiation for in-breast recurrence. Int J Radiat Oncol Biol Phys 2017; 98: 1028-1035.

53. Janssen S, Rades D, Meyer A et al. Local recurrence of breast cancer: conventionally fractionated partial external beam re-irradiation with curative intention. Strahlenther Onkol 2018; 194: 806-814.

54. Datta NR, Puric E, Klingbiel D et al. Hyperthermia and radiation therapy in locoregional recurrent breast cancers: a systematic review and meta-analysis. Int J Radiat Oncol Biol Phys 2016; 94: 1073-1087.

55. Hepel JT, Wazer DE. A comparison of brachytherapy techniques for partial breast irradiation. Brachytherapy 2012; 11: 163-175.

56. Edge SB, Compton CC. The American Joint Committee on Cancer: the 7th edition of the AJCC cancer staging manual and the future of TNM. Ann Surg Oncol 2010; 17: 1471-1474.

57. Moser EC, Vrieling C. Accelerated partial breast irradiation: the need for well-defined patient selection criteria, improved volume definitions, close follow-up and discussion of salvage treatment. Breast 2012; 21: 707-715.

58. Strnad V, Hannoun-Levi JM, Guinot JL et al. Recommendations from GEC ESTRO Breast Cancer Working Group (I): Target definition and target delineation for accelerated or boost Partial Breast Irradiation using multicatheter interstitial brachytherapy after breast conserving closed cavity surgery. Radiother Oncol 2015; 115: 342-348.

59. Strnad V, Major T, Polgar C et al. ESTRO-ACROP guideline: Interstitial multi-catheter breast brachytherapy as Accelerated Partial Breast Irradiation alone or as boost - GEC-ESTRO Breast Cancer Working Group practical recommendations. Radiother Oncol 2018; 128: 411-420.

60. Shah C, Vicini F, Shaitelman SF et al. The American Brachytherapy Society consensus statement for accelerated partial breast irradiation. Brachytherapy 2018; 17: 154-170.

61. Cox JD, Stetz J, Pajak TF. Toxicity criteria of the Radiation Oncology Group (RTOG) and the European Organization for Research and Treatment of Cancer (EORTC). Int J Radiat Oncol Biol Phys 1995; 31: 1341-1346.

62. Vicini FA, White J, Arthur D et al. NSABP B-39/RTOG 0413 protocol, A randomized phase III study of conventional whole breast irradiation (WBI) versus partial breast irradiation (PBI) for women with stage 0, I or II breast cancer. Available at: http:/ / www.rtog.org.

63. Wazer DE, Kaufman S, Cuttino L et al. Accelerated partial breast irradiation: an analysis of variables associated with late toxicity and long-term cosmetic outcome after highdose-rate interstitial brachytherapy. Int J Radiat Oncol Biol Phys 2006; 64: 489-495. 